Article

\title{
Impact of Malapposed and Overlapping Stents on Hemodynamics: A 2D Parametric Computational Fluid Dynamics Study
}

\author{
Manuel Lagache ${ }^{1,2,3}$, Ricardo Coppel ${ }^{1,2}$, Gérard Finet ${ }^{4}$, François Derimay ${ }^{4}\left(\mathbb{D}\right.$, Roderic I. Pettigrew ${ }^{5}$, \\ Jacques Ohayon ${ }^{1,3}$ and Mauro Malvè $6,7, *$ (D) \\ 1 Laboratory SYMME, Savoie Mont-Blanc University, 73000 Chambéry, France; \\ manuel.lagache@univ-smb.fr (M.L.); ricardocvmty@gmail.com (R.C.); jacques.ohayon@univ-smb.fr (J.O.) \\ 2 Savoie Mont-Blanc University, Polytech Annecy-Chambéry, 73370 Le Bourget du Lac, France \\ 3 Laboratory TIMC-IMAG, CNRS, UMR5525, Grenoble-Alpes University, 38400 Grenoble, France \\ 4 Department of Hemodynamics and Interventional Cardiology, Hospices Civils de Lyon and Claude Bernard \\ University Lyon 1, INSERM Unit 886, 69622 Lyon, France; gerard.finet@univ-lyon1.fr (G.F.); \\ Francois.derimay@chu-lyon.fr (F.D.) \\ 5 CEO, Engineering Health (EnHealth) and Executive Dean, Engineering Medicine (EnMed), \\ Texas A\&M University and Houston Methodist Hospital, Houston, TX 77030, USA; pettigrew@tamu.edu \\ 6 Department of Engineering, Public University of Navarra, 31006 Pamplona, Spain \\ 7 CIBER-BBN, Research Networking in Bioengineering, Biomaterials \& Nanomedicine, 50018 Zaragoza, Spain \\ * Correspondence: mauro.malve@unavarra.es
}

check for updates

Citation: Lagache, M.; Coppel, R.; Finet, G.; Derimay, F.; Pettigrew, R.I.; Ohayon, J.; Malvè, M. Impact of Malapposed and Overlapping Stents on Hemodynamics: A 2D Parametric Computational Fluid Dynamics Study. Mathematics 2021, 9, 795. https: / / doi.org/10.3390/ math9080795

Academic Editor: Omer San

Received: 10 February 2021

Accepted: 1 April 2021

Published: 7 April 2021

Publisher's Note: MDPI stays neutral with regard to jurisdictional claims in published maps and institutional affiliations.

Copyright: (C) 2021 by the authors Licensee MDPI, Basel, Switzerland. This article is an open access article distributed under the terms and conditions of the Creative Commons Attribution (CC BY) license (https:/ / creativecommons.org/licenses/by/ $4.0 /)$.

\begin{abstract}
Despite significant progress, malapposed or overlapped stents are a complication that affects daily percutaneous coronary intervention (PCI) procedures. These malapposed stents affect blood flow and create a micro re-circulatory environment. These disturbances are often associated with a change in Wall Shear Stress (WSS), Time-averaged WSS (TAWSS), relative residence time (RRT) and oscillatory character of WSS and disrupt the delicate balance of vascular biology, providing a possible source of thrombosis and restenosis. In this study, 2D axisymmetric parametric computational fluid dynamics (CFD) simulations were performed to systematically analyze the hemodynamic effects of malapposition and stent overlap for two types of stents (drug-eluting stent and a bioresorbable stent). The results of the modeling are mainly analyzed using streamlines, TAWSS, oscillatory shear index (OSI) and RRT. The risks of restenosis and thrombus are evaluated according to commonly accepted thresholds for TAWSS and OSI. The small malapposition distances (MD) cause both low TAWSS and high OSI, which are potential adverse outcomes. The region of low OSI decrease with MD. Overlap configurations produce areas with low WSS and high OSI. The affected lengths are relatively insensitive to the overlap distance. The effects of strut size are even more sensitive and adverse for overlap configurations compared to a well-applied stent.
\end{abstract}

Keywords: hemodynamics; overlap; malapposition; stent; stenosis; thrombosis

\section{Introduction}

Percutaneous coronary intervention (PCI) with modern drug-eluting stents (DES) has revolutionized the treatment of arterial diseases. However, their benefits could be compromised by potential complications such as restenosis and thrombosis [1-4]. Complications of PCI continue to be a concern, with approximately 1-2\% of stent patients dying from thrombotic occlusions and 10-15\% requiring additional interventions due to restenosis [3-7]. The deployment of a coronary stent near a complex atherosclerotic lesion (i.e., located close to a bifurcation, near concomitant lesions or with eccentric plaque formation) may promote the occurrence of gaps between the vessel wall and the struts, defined as malapposition distance (MD) [8-10]. It appears in up to $33 \%$ of implanted DES and up to $75 \%$ of patients with very late (i.e., $>1$ year) stent thrombosis [10-12]. Furthermore, the use of two partially 
overlapped stents (i.e., with a certain overlap distance (OD)) may be necessary in the event of incomplete coverage of lesions with a single stent. Approximately $30 \%$ of PCI patients requiring stenting are in situations where stents overlap [7].

Stent implantation by itself generates geometric irregularities on the vascular walls that modify the hemodynamics along the entire length of the stent [13-15]. Local hemodynamic parameters, in particular abnormal wall shear stress (WSS), critically affect the evolution of atherosclerosis plaque and have been associated with an increased risk of thrombosis or restenosis $[1,2,5,6,16]$. Moreover, stent malapposition and overlapping have been associated with hemodynamic disturbances that may increase the risks of adverse clinical outcomes [2,8,10,17-22].

Several studies have been performed to analyze how the presence of stents perturbs the hemodynamics in a vessel. Computational fluid dynamics (CFD) calculations performed on simplified stent models inside an idealized coronary artery $[5,6,8,10,22]$ have been used to investigate the effects of malapposed struts on the blood flow. These studies have shown that, as the MD increases, recirculation regions located near the wall tend to grow downstream from the malapposed struts until a critical MD is reached. Above this MD threshold, recirculation regions gradually reduce in size until the interaction between the wall and the misaligned struts disappears. Moreover, it has been reported that the regions near the malapposed struts (more specifically at the gaps between the wall and the struts) are subjected to high wall shear stress $[5,6,10]$ and that the abnormal region tends to increase with MD [6]. While several studies have been conducted to highlight the hemodynamic perturbations induced by malapposed stents, few are devoted to studying overlapping configurations. An in vitro study by [18], using the particle image velocimetry technique with a vascular phantom under physiological flow conditions, showed that overlapping sections tend to disrupt the flow and create a WSS deficiency. [17,19] obtained similar conclusions after performing 3D CFD simulations based on realistic artery-stents geometries reconstructed from computed tomography images. Additionally, a 2D CFD study by [22] revealed also that strut overlapping increases the amount of flow recirculation compared to non-overlapped segments. Moreover, congruent struts (i.e., one strut on top of the other) have been identified as critical configurations due to the major flow disturbance that they produce [22] and the important drop of WSS around them [17].

Although complex 3D studies have provided promising results, identifying areas where malapposed and/or overlapping struts can lead to the development of abnormal WSS and significantly disturb blood flow on patient-specific geometries, no practical information has been given yet to clinicians to assist them in their choice when a stent is incorrectly positioned.

This lack of knowledge is mainly due to the difficulty: (1) to model complex configurations due to the computation times required (often incompatible with operational workflow) and (2) to identify the disturbance effect of each of the different parameters separately. Using static CFD models based on 2D geometries, researchers have found the location and general tendency of disturbed flow regions for different degrees of strut malapposition and overlapping $[6,10,22]$. However, to our knowledge, a complete parametric study designed to highlight critical malapposition and overlapping stent configurations, for which flow disturbance over a cardiac cycle becomes significant, has never been conducted.

Therefore, in this study, we designed and used two-dimensional parametric CFD models to investigate the hemodynamic effect of several stent malapposition and overlapping configurations while considering (1) pulsatile flow conditions, (2) the non-Newtonian nature of blood flow and (3) the most commonly used flow-related indices to assess the hemodynamic impact on the vessel wall over a cardiac cycle.

The use of 2D axisymmetric models requires much lower computational costs and enables a systematic evaluation of the effect of all relevant geometrical parameters (malapposition and overlapping distances) by means of several sequential simulations. The identification of specific critical configurations that can promote restenosis and thrombosis and clearly describe the temporal and spatial evolution of hemodynamic disturbances 
remain the main objectives of this study. The present study is complementary to the patientspecific 3D studies by providing general information and cut-off values for overlapping and malapposed distances. The purpose of this work is to provide general criteria on the effect of misalignment and overlapping distances and not patient-specific information (which must be assessed for each patient). The results could provide a new decision-making tool for cardiologists by predicting the risks of complications related to malapposition and overlapping.

\section{Materials and Methods}

Two distinct CFD Models of stented segments of coronary arteries were considered. The first one mimics several cases of a single malapposed stent, while the second account for overlapping stent configurations. Furthermore, all the boundary conditions and constitutive laws used in these models will be described in the following sections, as well as the chosen hemodynamic metrics to evaluate the impact of each configuration on the vessel wall.

\subsection{Parametric CFD Models of Malapposed and Overlapped Stents}

\subsubsection{Geometries}

Hemodynamic disturbances produced by the stent struts near the arterial wall were studied numerically with the CFD approach. Moreover, 2D axisymmetric geometries modeling the two "stent-artery" configurations of interest (i.e., malapposition and overlapping) were used to perform dynamic flow analyses (Figure 1A,B). The geometrical parameters used to define and design the idealized "stent-artery" were as follows: malapposition and overlapping distances (i.e., MD and OD) for the two models of interest. Realistic diversity in clinical data was investigated by varying MD $0 \mu \mathrm{m} \leq \mathrm{MD} \leq 450 \mu \mathrm{m}$ and $\mathrm{OD}$ (in the overlapping range of 2 to 3 struts). Moreover, two strut sizes were considered in this study. The first one is a Cobalt-Chromium drug-eluting stent (CC-DES) (Synergy, Boston Scientific, Marlborough, MA, USA) with a section of $85 \mu \mathrm{m} \times 90 \mu \mathrm{m}$ (i.e., Height $(\mathrm{H}) \times$ Width $(\mathrm{W})$ ). The second one is a bioresorbable stent (BVS, Abbot, Abbott Park, IL, USA) with a thicker section of $150 \mu \mathrm{m} \times 215 \mu \mathrm{m}$. The diameter of the artery lumen was taken as $3 \mathrm{~mm}$. Once deployed, the inter-strut distance is $2 \mathrm{~mm}$ for both types of stents. Therefore, the total length of the stents is $10.54 \mathrm{~mm}$ and $11.29 \mathrm{~mm}$ for CC-DES and BVS respectively. The insertion of the apposed struts in the arterial wall has also been considered with a strut indentation of $0.15 * \mathrm{H}+20 \mu \mathrm{m}$ (see Figure $1 \mathrm{~A}$ inner box). A luminal protrusion caused by the stent struts in contact with the arterial walls is also introduced to each model with the aim of estimating with more accuracy the flow recirculation due to the presence of the struts and the associated hemodynamics variables (see Figure 1A,B). The latter could be in fact slightly underestimated, if the struts are just apposed on the arterial walls.
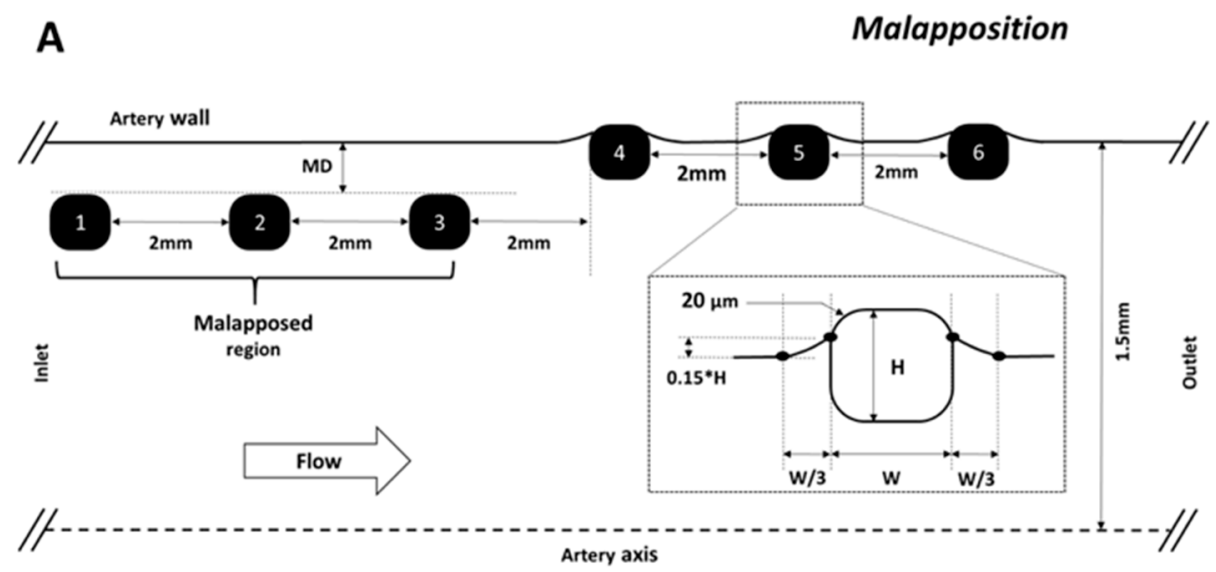

Figure 1. Cont. 


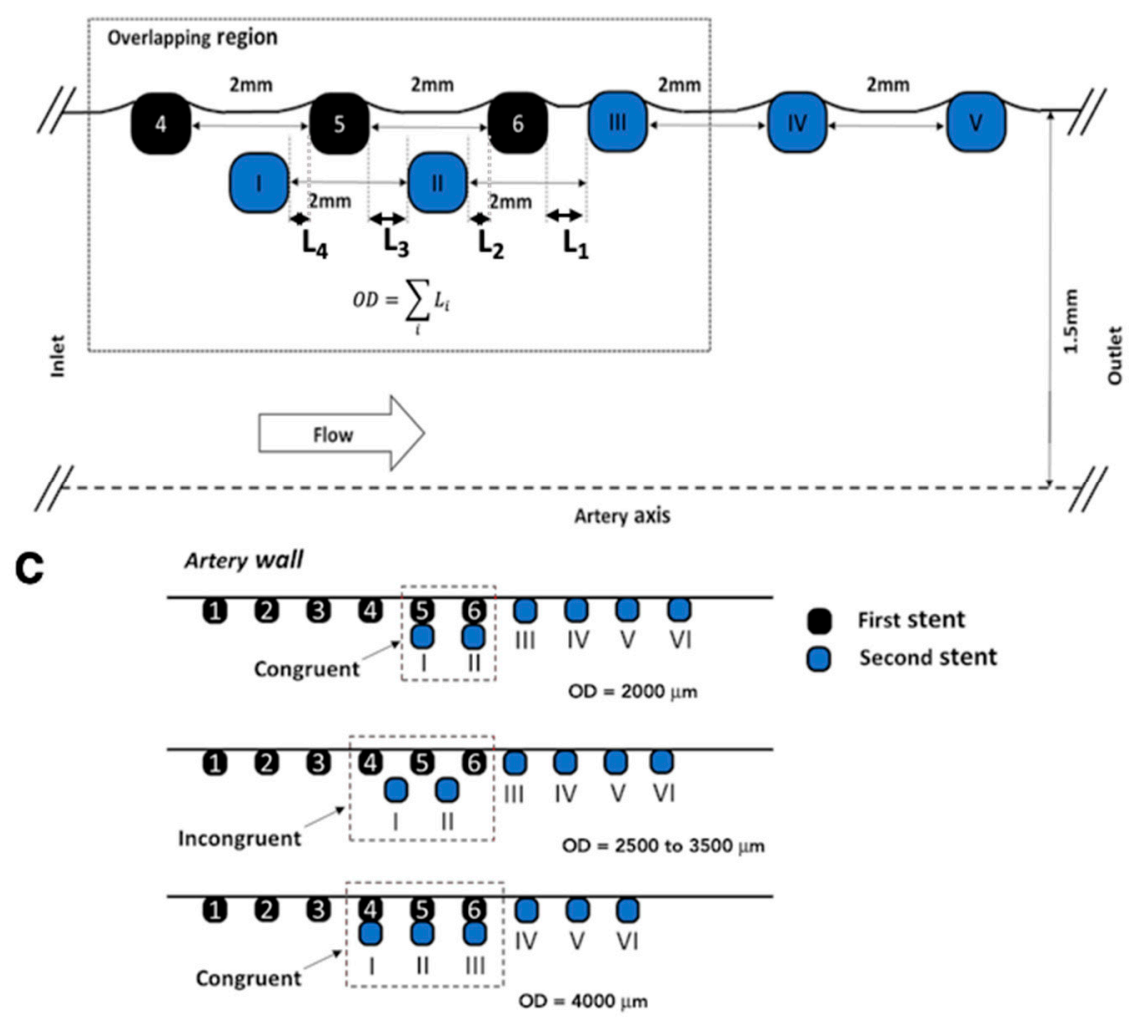

Figure 1. (A) Single stent geometry with three malapposed struts (\# 1,2, and 3 ) and three correctly apposed struts (\# 4, 5, and 6) and (B) two overlapping stents (first stent: struts \# 1 to 6, second stent: struts \# I to (VI) and (C) 3 overlapping configurations, with two congruent struts, with incongruent struts and three congruent struts.

\subsubsection{Studied Malapposition Configurations}

This strut configuration is displayed in Figure 1A. It illustrates one stent with three misaligned struts and three correctly apposed ones. The MD of the first three struts was between 0 and $450 \mu \mathrm{m}$ for both stents (i.e., CC-DES and BVS). The three apposed struts were placed downstream and remained fixed for all simulations. The following configurations were studied: for the CC-DES: MD = 0, 40, 60, 80, 115, 130, 150, 180, 225, 300 and $450 \mu \mathrm{m}$ (i.e., $n=11$ cases), and for the BVS: $\mathrm{MD}=0,40,80,115,150,180,225,300$ and $450 \mu \mathrm{m}$ (i.e., $n=9$ cases). When $\mathrm{MD}=0 \mu \mathrm{m}$ the six struts are correctly apposed (i.e., total stented artery length of 10.54 and $11.29 \mathrm{~mm}$ for CC-DES and BVS, respectively), these two specific cases (one for each stent) will be considered as the optimal clinical configurations. A total of 20 distinct configurations were studied.

\subsubsection{Studied Overlapping Configurations}

This strut configuration is illustrated in Figure 1B,C. This configuration corresponds to the partial overlapping of 2 stents. This overlapping is for example used to treat arteries with multistenosis, bifurcations... The OD was between $2000 \mu \mathrm{m}+2 \mathrm{~W}$ (strut width) and $4000 \mu \mathrm{m}+3 \mathrm{~W}$ (strut width). For reasons of simplicity and homogeneity between the two stents, these distances will be named without considering the width of the struts (different for the two stents). Two types of geometric configurations were considered, congruent and incongruent struts $[17,22]$. In the first case, the well-apposed and overlapping struts are stacked one on top of the other, forming a higher obstacle. In the second case, both struts are separated, leaving a gap between the overlapped one and the vessel wall (see Figure 1B). For the two stent types, simulations were performed for the following configurations: $\mathrm{OD}=2000,2500,3000,3500$ and $4000 \mu \mathrm{m}(n=2 \times 5$ cases $)$. Notice that when 
$\mathrm{OD}=2000 \mu \mathrm{m}$ there are two pairs of congruent struts and when $\mathrm{OD}=4000 \mu \mathrm{m}$ there are three pairs of congruent struts and for intermediate cases (i.e., from OD $=2500$ to $3500 \mu \mathrm{m}$ ) there are incongruent struts at the overlapping section. A total of 10 distinct simulations were performed.

\subsubsection{Constitutive Law}

Blood density was assumed to be constant with a value of $1060 \mathrm{~kg} \mathrm{~m}^{-3}$. The nonNewtonian nature of blood flow was taken into account using the Carreau-Yasuda model [19]:

$$
\mu=\mu_{\infty}+\left(\mu_{0}-\mu_{\infty}\right)\left[1+(\lambda \dot{S})^{2}\right]^{(m-1) / 2}
$$

where $\mu$ is the dynamic viscosity, $\mu_{0}$ and $\mu_{\infty}$ are the viscosity values at zero and infinity shear rate, respectively, $\dot{S}$ is the shear rate, $\lambda$ is the time constant, and $\mathrm{m}$ is the power-law index. These fluid constants values were taken from [19] and are used in [20] among other studies: $\mu_{\infty}=0.0035 \mathrm{~Pa} \mathrm{~s}, \mu_{0}=0.25 \mathrm{~Pa} \mathrm{~s}, \lambda=25 \mathrm{~s}$ and $\mathrm{m}=1 / 4$.

\subsubsection{Boundary Conditions}

The blood flow was considered laminar and unsteady. The Reynolds number (Re) for the present simulations was 252 .

The artery wall and struts were assumed to be rigid with the no-slip condition and a time-dependent velocity profile (see Figure 2) was applied at the inlet of the axisymmetric domain to mimic the pulsatile behavior of coronary blood flow (with a time period equal to $0.908 \mathrm{~s}$ ). The physiological waveform was adapted from [23]. The same velocity profile was used for the outlet to guarantee mass conservation. The inlet and outlet regions were extended about six times the radius of the artery. These lengths were chosen with precision after the first series of simulations that proved that these extensions were sufficient to provide a fully developed flow. Additionally, in order to minimize the effect of the initial transients, two complete cardiac cycles were simulated for all the configurations studied and only the results of the second cycle were considered. A third cycle was performed as a test-case with a malapposition configuration with $\mathrm{MD}=150 \mu \mathrm{m}$. However, no significant difference in velocity responses was found compared to the results from the second cycle. These different tests ensured the quality of the results.
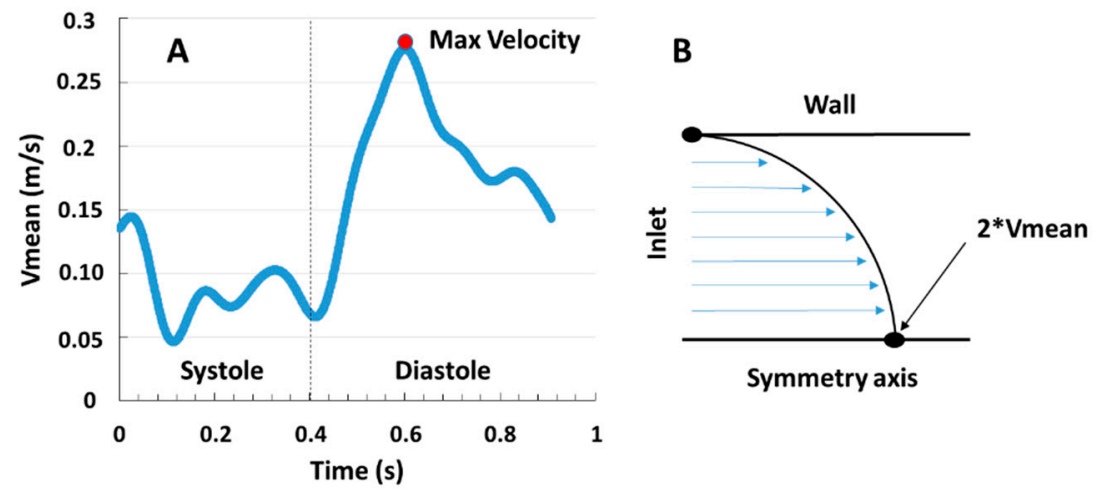

Figure 2. (A) Physiological velocity waveform adapted from Davies et al. (2006) and (B) Velocity profile imposed at the inlet.

\subsubsection{Computational Fluid Dynamics Simulations}

An APDL program file (ANSYS v19.2, ANSYS Inc., Canonsburg, PA, USA) was developed for the two studied configurations (malapposition and overlapping) in order to simplify the parameterization. The finite element problems are then generated and solved automatically after the selection of the different parameters. This parametric program allows easy utilization (for a stent designer, a clinician...). ANSYS FLUENT was used to mesh the fluid domain with hexahedral and triangular elements and calculate the velocity 
and pressure distributions. Mesh refinement was performed on the regions around the struts and vessel walls to improve the accuracy of the computations.

The malapposition configuration with MD $=150 \mu \mathrm{m}$ was used to perform an analysis of the influence of the mesh on the convergence of the results. A baseline element size was defined for the different regions (Zone 1: central zone of the artery, Zone 2: intermediate zone of the artery and Zone 3 in the vicinity of the struts). For each of these zones, the average element sizes were: zone $1=5 \mu \mathrm{m}$, zone $2=3 \mu \mathrm{m}$, zone $3=1.5 \mu \mathrm{m}$. The mesh obtained with these values was identified as the baseline mesh. A refined mesh was obtained by dividing all element sizes by two (i.e., zone $1=2.5 \mu \mathrm{m}$, zone $2=1.5 \mu \mathrm{m}$, zone $3=0.75 \mu \mathrm{m}$ ). In addition, a further refinement operation was applied to all lines representing the struts and wall of the artery. Approximately 60,000 elements were obtained for the baseline mesh and 180,000 for the refined mesh. After performing a steady-state analysis, the velocity profiles obtained for the two mesh densities were compared and were found to be similar. In addition, the maximum velocity in the whole fluid domain obtained with the base mesh $(0.539993 \mathrm{~m} / \mathrm{s})$ and the one obtained with the refined mesh $(0.540401 \mathrm{~m} / \mathrm{s})$ showed a difference of less than $0.1 \%$.

A similar approach was carried out for an overlapping configuration with $\mathrm{OD}=2000 \mathrm{~m}$. The conclusions were similar.

The time step was $0.001 \mathrm{~s}$ (908 time-steps per cardiac cycle) and convergence criteria for both pressure and velocity residuals were $10^{-6}$.

\subsection{Hemodynamic Metrics}

WSS and its derived indexes, time-averaged WSS (TAWSS) and oscillatory shear index (OSI), are of great interest while studying the impact of stent struts on hemodynamics. The definitions of these parameters are recalled below.

TAWSS represents the average stress magnitude experienced by the vascular wall during a cardiac cycle and is derived as follows:

$$
\text { TAWSS }=\frac{1}{\mathrm{~T}} \int_{0}^{\mathrm{T}}|\mathrm{WSS}| \mathrm{dt}
$$

where T denotes the period of the cardiac cycle and |WSS| the modulus of the vector WSS. TAWSS is insensitive to the direction of the WSS vector.

OSI is a non-dimensional scalar used to evaluate the oscillatory nature of vascular flows (i.e., how much the WSS vectors change their direction over a cycle) and is calculated as follows:

$$
\text { OSI }=\frac{1}{2}\left(1-\frac{\left|\int_{0}^{\mathrm{T}} \mathrm{WSS} \mathrm{dt}\right|}{\int_{0}^{\mathrm{T}}|\mathrm{WSS}| \mathrm{dt}}\right)
$$

OSI varies between 0 and 0.5 with a value of 0 when there is no oscillatory WSS and 0.5 when it is fully oscillatory.

The RRT measures how long the particles stay near the wall of the vessel. Longer time of contact between atherogenic particles and the arterial wall could cause a high risk of atherosclerosis formation $[20,24,25]$. High RRT $\left(\right.$ RTT $\left.>10 \mathrm{~Pa}^{-1}\right)$ is recognized as critical for atherogenesis and in-stent restenosis [20]. Thus, RRT was defined as follows:

$$
\mathrm{RRT}=\left(\frac{1}{(1-2 \mathrm{OSI}) \mathrm{TAWSS}}\right)
$$

As this previous definition shows, RRT combines the information provide by TAWSS and OSI. 


\subsection{Pathological OSI, TAWSS and RRT Thresholds}

It is generally accepted that an abnormally low WSS increases the risk of restenosis $[1,14,26,27]$ A TAWSS $<0.5 \mathrm{~Pa}$ is a common threshold value to indicate low WSS over the cardiac cycle $[5,8,19]$. On the other hand, high shear stresses (TAWSS $>2.5 \mathrm{~Pa}$ ) have been associated with plaque rupture [28] that could lead to thrombosis. In addition, high shear stresses have been reported to increase the activation of platelets which are the main cellular components of a thrombus $[2,6,10,20,29]$. Regarding oscillatory flow, OSI $>0.1$ was associated with an increased risk of arterial narrowing $[16,19,30,31]$. Additionally, other authors have reported that thrombus formation is enhanced at areas characterized by high OSI because slow and reversed flow promotes platelet aggregation $[1,29]$

In this work the following thresholds were used: TAWSS $<0.5$ Pa increases the risk of restenosis, TAWSS $>2.5 \mathrm{~Pa}$ promotes thrombosis and OSI $>0.1$ promotes both restenosis and thrombosis. RRT $>10 \mathrm{~Pa}^{-1}$ promotes restenosis. The threshold for RRT is variable between studies in the literature. For instance, it is $5 \mathrm{~Pa}^{-1}$ in [20] and $10 \mathrm{~Pa}^{-1}$ in [25]. In the present study, the RRT should be less than $8 \mathrm{~Pa}^{-1}$. According to [24], RRT is recommended as a unique and robust measure of low and oscillating shear flow.

\section{Results}

\subsection{Results for Malapposition}

\subsubsection{Effect of Malapposition on the Velocity Field}

Figure 3 displays the most relevant streamlines in the vicinity of the first stent strut at the diastolic peak (See Figure 2) when the average flow velocity is the highest and recirculation regions reach their maximum extensions. For the well-apposed configuration (see MD $=0 \mu \mathrm{m}$ for both the CC-DES and BVS stents in Figure 3), there were relatively small recirculation regions upstream and downstream from the apposed strut. It should be noticed that the recirculation zone is much larger for the BVS stent. As soon as the stent began separate from the wall (i.e., with further increments of MD), upstream recirculation disappeared but the one located downstream from the malapposed strut started growing and moving to the right until it disappeared as well (see MD $=115 \mu \mathrm{m}$ for CC-DES stent and $\mathrm{MD}=300 \mu \mathrm{m}$ for BVS stent in Figure 3). As expected, flow disturbance was more enhanced for the large strut (i.e., BVS stent). Moreover, flow accelerated through the wall separation gap as MD increased giving, as a result, a larger velocity gradient.

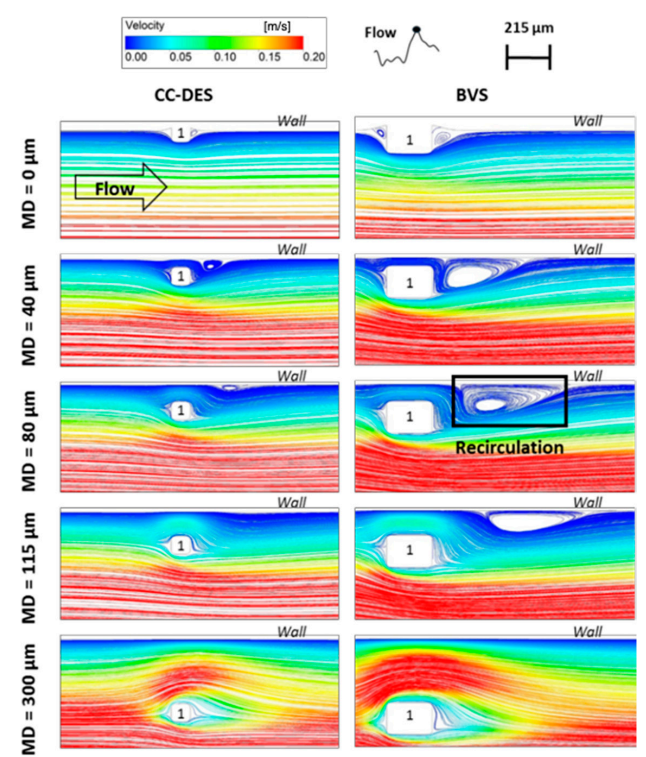

Figure 3. Most relevant streamlines in the vicinity of the first strut at the diastolic peak induced by Cobalt-Chromium drug-eluting stent (CC-DES) and bioresorbable stent (BVS) stent for $\mathrm{MD}=0,40,80,115$ and $300 \mu \mathrm{m}$. 


\subsubsection{Effect of Malapposition on TAWSS}

Figure 4 illustrates the TAWSS distribution along the arterial wall for the whole extension of the stent for the most pertinent MD values. First, the normal TAWSS magnitude of about $1.5 \mathrm{~Pa}$ (i.e., the shear stress value for a vessel without stent) was locally disturbed even for well-apposed stent. Furthermore, peaks of TAWSS, sometimes with maximum values above $2.5 \mathrm{~Pa}$ (see $\mathrm{MD}>80 \mu \mathrm{m}$ in Figure 4), developed in the malapposed region. The amplitude of these peaks increased with MD values and was higher for BVS stent (compared to CC-DES stent). In the well-apposed area, there were no TAWSS peaks for all values of MD. The TAWSS plateaus between two well-apposed struts (1.5 Pa) were slightly modified. The amplitude of the plateaus between the three well-applied struts rapidly converges to the values of the plateaus of a well-applied stent. These perturbations were more significant for BVS stents than for CC-DES stents.
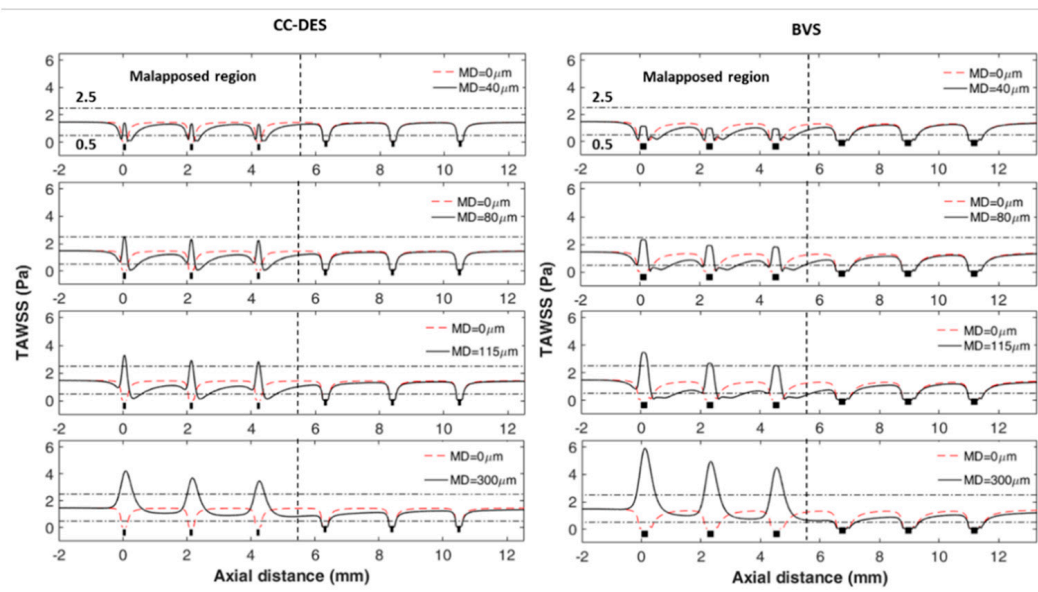

Figure 4. Time-averaged wall shear stress (TAWSS) distribution for the malapposition configuration. For simplicity reasons, only five representative configurations are displayed for each strut size $(\mathrm{MD}=0,40,80,115$ and $300 \mu \mathrm{m})$. Strut locations are indicated with black rectangles. Notice that axial distance $=0 \mathrm{~mm}$ corresponds to the location of the first malapposed strut. Three TAWSS ranges can be defined: TAWSS $<0.5 \mathrm{~Pa}$ (Low TAWSS), $0.5<$ TAWSS $<2.5 \mathrm{~Pa}$ (Normal TAWSS) and TAWSS $>2.5 \mathrm{~Pa}$ (High TAWSS).

For small malapposition distances (see $\mathrm{MD}=40,80$ and $115 \mu \mathrm{m}$ for both strut sizes in Figure 4), some segments of the vessel wall in the malapposed region were below $0.5 \mathrm{~Pa}$, indicating an abnormally low TAWSS. These segments, with low values, vanished for $\mathrm{MD}=300 \mu \mathrm{m}$ (for both types of stents). These areas, with low shear stress, are located near and downstream of the struts. Additionally, BVS struts produced larger regions with low TAWSS.

\subsubsection{Effect on the Oscillatory Character of WSS Caused by Malapposed Strut}

Figure 5 displays the OSI distribution along the stented region of the arterial wall's five most representative MD values. First, in the case of a correctly apposed stent (see $\mathrm{MD}=0 \mu \mathrm{m}$ for both strut sizes in Figure 5), the effect of recirculation was similar for all the struts. However, as the stent began to separate from the wall, high peaks of OSI appeared downstream from each malapposed strut. These peaks were present for small wall separations but disappeared with further increments of malapposition distance (see Figure $5, \mathrm{MD}=115 \mu \mathrm{m}$ for CC-DES and MD $=300 \mu \mathrm{m}$ for BVS). These results suggest that malapposed struts promote significant flow recirculations during the cardiac cycle, which confirms the flow perturbation in Figure 3 by considering the temporal evolution of the flow recirculation regions. 

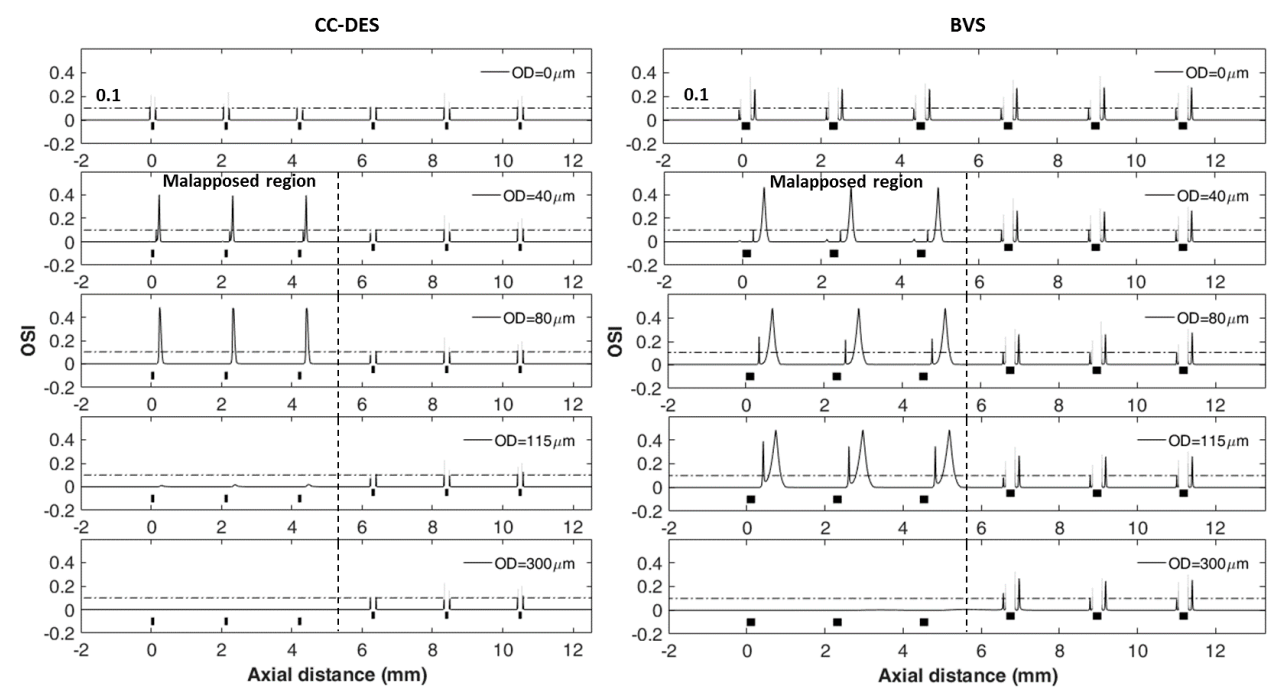

Figure 5. OSI distribution for malapposition configuration. For simplicity reasons, only five representative configurations are displayed for each strut size $(\mathrm{MD}=0,40,80,115$ and $300 \mu \mathrm{m})$. Strut locations are indicated with black rectangles. Notice that axial distance $=0 \mathrm{~mm}$ corresponds to the location of the first strut. Two OSI ranges can be defined: OSI $<0.1$ (Low recirculation) and OSI $>0.1$ (High recirculation).

\subsubsection{Effect of Malapposition on RRT}

Figure 6 displays the RRT distribution along the stented region of the arterial wall across the stented region, for the five most representative $M D$ values (MD $=0,40,80$, 115 , and $300 \mu \mathrm{m}$ ). Firstly, well-apposed struts produce peaks in the distribution of RRT located around each strut, with values significantly above the thresholds. These peaks are significantly larger for BVS stents with larger struts. They split into several peaks at low MD values. Therefore, the arterial wall affected by RRT values above the threshold is divided into several critical areas, very close to each other. This phenomenon is much more important when the dimensions of the struts increase (for BVS stent). On the other hand, all MD values do not disturb the downstream RRT distributions (for the three well-apposed struts). When MD is higher or equal to $115 \mu \mathrm{m}$ for the CC-DES stent and $300 \mu \mathrm{m}$ for the BVS stent, the amplitude of the peaks (for the malapposed struts) decreases drastically and is significantly below the thresholds.

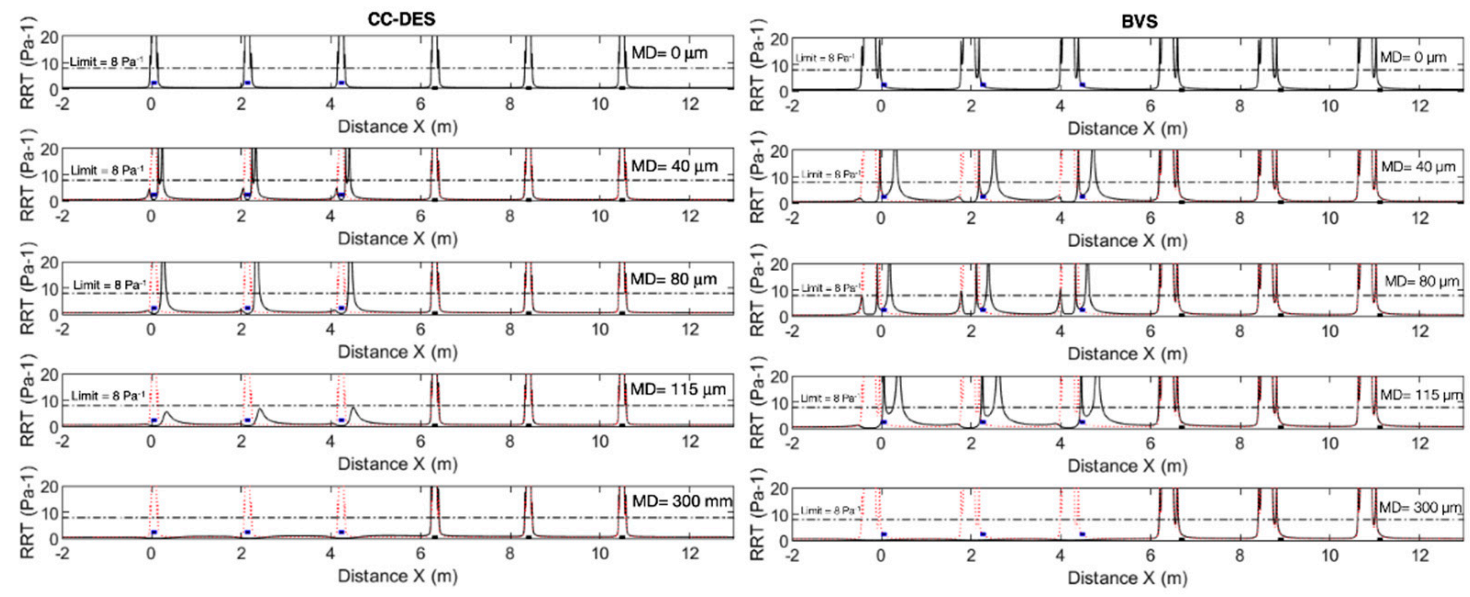

Figure 6. Relative residence time (RRT) distribution for the malapposition configuration. For sake of simplicity, only five representative configurations are displayed for each strut size (MD =0,40, 80, 115 and $300 \mu \mathrm{m})$. Strut locations are indicated with black rectangles. Notice that axial distance $=0 \mathrm{~mm}$ corresponds to the location of the first malapposed strut. 


\subsubsection{Relationship between OSI and TAWSS for Malapposion Configuration}

Figure 7 plots the distribution of TAWSS versus OSI for all the nodal solutions on the arterial wall. Only the configurations including an OSI peak higher than 0.1 in the malapposed region were considered $(\mathrm{MD}=40,60$ and $80 \mu \mathrm{m}$ for CC-DES stent and $\mathrm{MD}=40,80,115,150$ and $180 \mu \mathrm{m}$ for BVS stent). The high OSI values were always associated with low TAWSS $<0.5 \mathrm{~Pa}$.
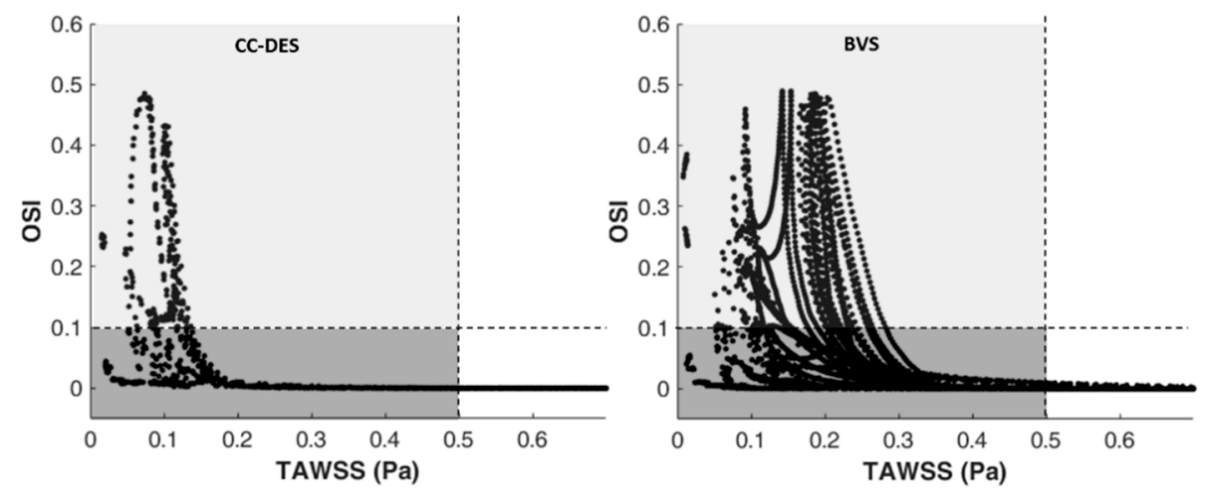

Figure 7. OSI vs. TAWSS plots. Each point represents a nodal solution of the arterial wall. The considered configurations were $\mathrm{MD}=40,60$ and $80 \mu \mathrm{m}$ for CC-DES stent and $\mathrm{MD}=40,80,115,150$ and $180 \mu \mathrm{m}$ for BVS stent.

\subsubsection{Effect of MD Distance on Arterial Wall Extent with a Risk of Restenosis/Thrombus}

Figure 8 displays the evolution of the total wall length affected by low TAWSS $(<0.5 \mathrm{~Pa})$, high TAWSS $(>0.5 \mathrm{~Pa})$ and high OSI $(>0.1)$ versus malapposition distance. First of all, the evolution of the different affected lengths was similar for both stents, but much more significant for the BVS one. For both stents: (1) the total wall lengths affected by high OSI and low TAWSS increased until they reached a maximum value followed by a decreasing tendency that finished in a plateau (2) The wall extension affected by a high OSI reached a maximum before that corresponding to low TAWSS (i.e., at about one strut height) and (3) With regard to the total length affected by a high TAWSS, it has always tended to increase. Three zones were identified (see Figure 7), the first one prone to develop restenosis, the second one with risk of developing both restenosis and thrombosis and the last one prone to develop mainly thrombosis.
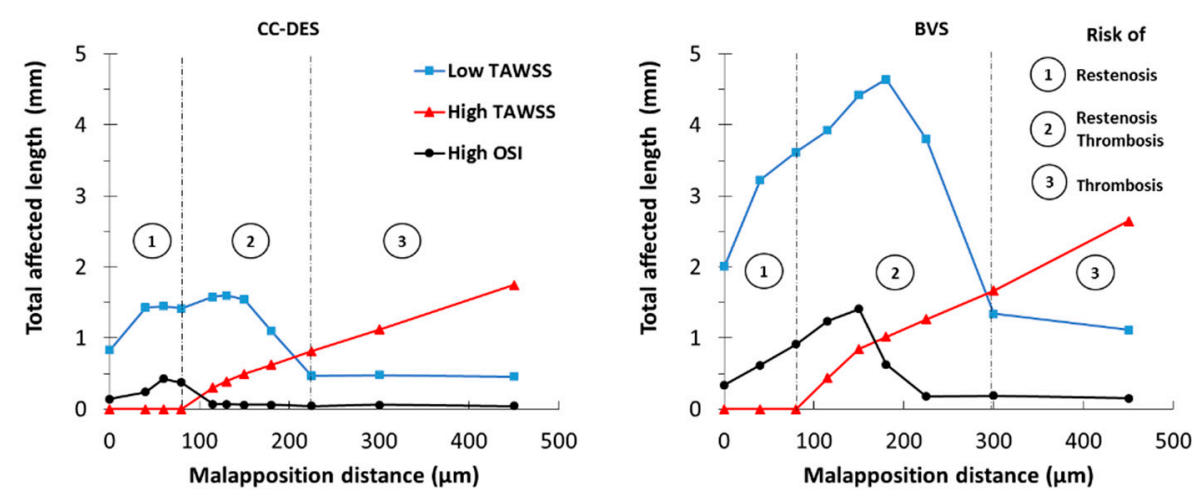

Figure 8. Evolution of affected arterial length vs. malapposition distance (MD). High risk of restenosis (zone 1), restenosis and thrombosis (zone 2) and mainly thrombosis (zone 3).

Malapposed CC-DES struts increased the total extension of the affected wall up to $1.6 \mathrm{~mm}($ at $\mathrm{MD}=130 \mu \mathrm{m})$ for low shear stress, $1.75 \mathrm{~mm}(\mathrm{MD}=450 \mu \mathrm{m})$ for high shear stress, and $0.42 \mathrm{~mm}$ (at MD $=60 \mu \mathrm{m}$ ) for high flow oscillation. For malapposed BVS struts, the total affected wall raised up to $4.64 \mathrm{~mm}$ (at MD = $180 \mu \mathrm{m}$ ) for low shear stress, $2.65 \mathrm{~mm}$ $(\mathrm{MD}=450 \mu \mathrm{m})$ for high shear stress, and $1.41 \mathrm{~mm}(\mathrm{MD}=150 \mu \mathrm{m})$ for high flow oscillation. 
These affected lengths were significantly larger for BVS struts (up to 2.9 times for low TAWSS, 1.51 times for high TAWSS, and 3.31 times for high OSI). The areas of the wall with high risk of restenosis/thrombus increase drastically with the dimensions of the struts.

\subsection{Results for Overlapping}

\subsubsection{Effect of Overlapping on the Velocity Field}

Figure 9 depicts the effect of different OD levels on the blood flow at the diastolic peak when recirculation regions reach their maximum extensions in the overlapping section for the diastolic peak. For congruent struts (i.e., with OD $=2000$ and $4000 \mu \mathrm{m}$, see Figure 9), large recirculation regions appeared downstream from each pair of piled struts. With intermediate OD values (i.e., for incongruent struts with $\mathrm{OD}=3000 \mu \mathrm{m}$, see Figure 9), these recirculation regions moved downstream from each overlapping strut and reduced their extensions compared to congruent configuration. Additionally, small recirculation regions reappeared downstream from each well-apposed strut. Moreover, flow acceleration occurred through the gap between the overlapping struts and the vessel wall. Finally, similar to malapposition configurations, flow disturbance was more notorious for large struts (i.e., BVS stent).

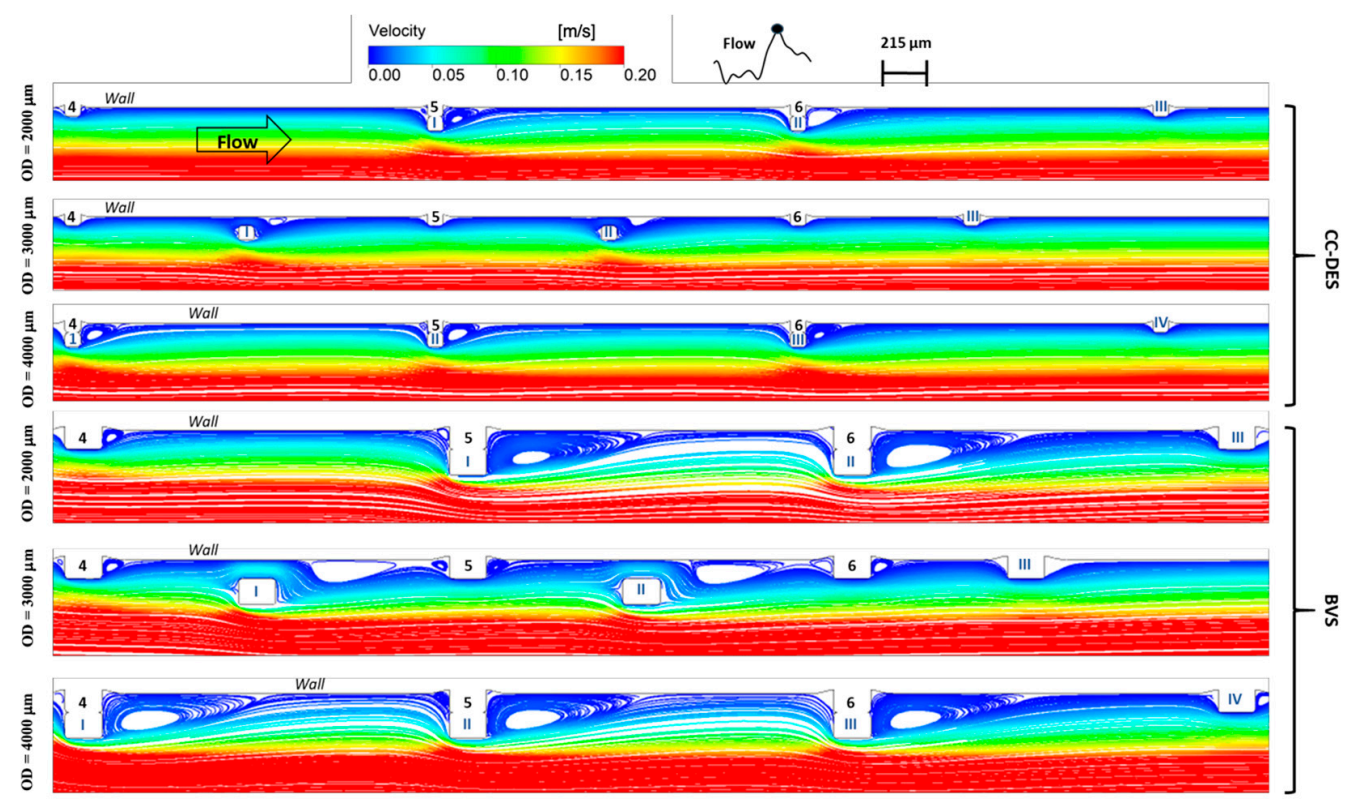

Figure 9. Streamlines at diastolic peak for overlapping stents. For simplicity reasons, just three representative configurations are presented for each strut size.

\subsubsection{Effect of Overlapping on TAWSS}

Figure 10 illustrates the TAWSS distribution at the overlapping region of CC-DES and BVS stents. First, the perturbation of the TAWSS distribution is localized in this overlapping zone and up to the first strut downstream. TAWSS peaks appear at the location of the overlapping struts for configuration with incongruent stents (blue rectangles in OD $=1000 \mu \mathrm{m}$, see Figure 10). Moreover, for all OD values, some regions with a TAWSS below $0.5 \mathrm{~Pa}$ (abnormally low value) appeared on the arterial wall. For congruent configurations (i.e., $\mathrm{OD}=0$ and $2000 \mu \mathrm{m}$, see Figure 10) and small strut size, flow reattachment downstream from each pair of piled struts allowed to recover a normal TAWSS value (1.5 Pa). However, for large struts, the perturbation was so significant that the normal TAWSS level could not be reached in the overlapping region. 

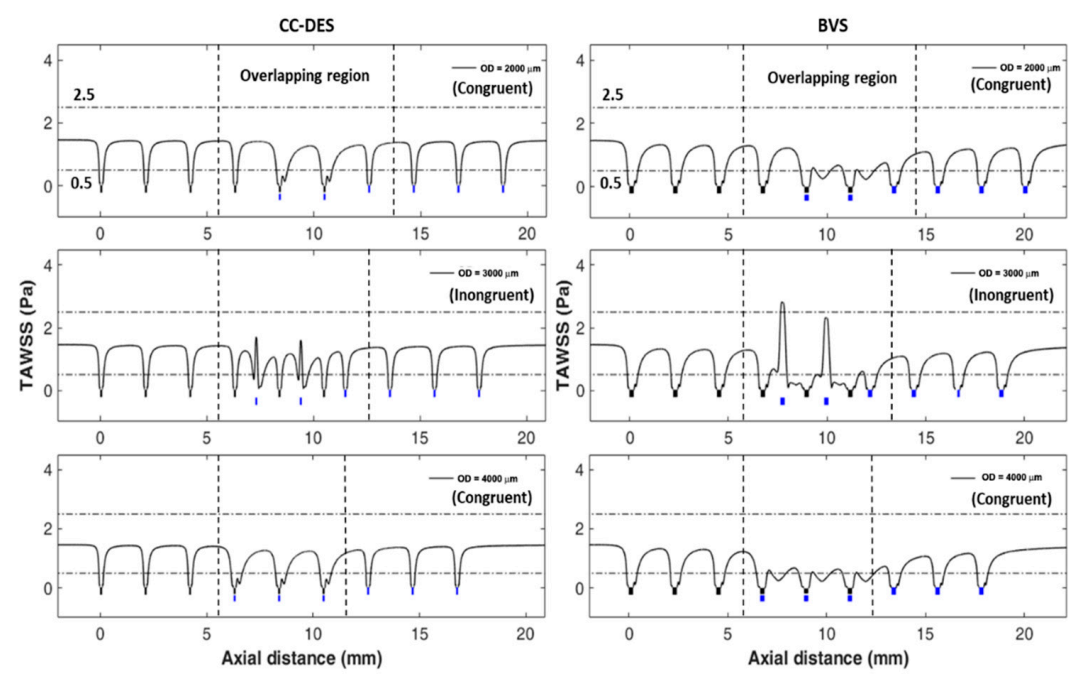

Figure 10. TAWSS distribution for overlapping configuration. For simplicity reasons, three representative configurations are displayed for each strut size. Strut locations on the $\mathrm{X}$-axis are indicated with black and blue rectangles for the first and second strut respectively. Notice that axial distance $=0 \mathrm{~mm}$ corresponds to the location of the first stent. Three ranges can be defined: TAWSS $<0.5 \mathrm{~Pa}$ (Low TAWSS), $0.5<$ TAWSS < 2.5 Pa (Normal TAWSS) and TAWSS > 2.5 Pa (High TAWSS).

\subsubsection{Effect on the Oscillatory Character of WSS Due to Overlapping}

Figure 11 displays the OSI distribution of overlapping CC-DES and BVS stents. First, the most important peaks of OSI were located at the overlapping region. Moreover, the distribution of peaks was different for congruent and incongruent cases. When the struts of two overlapping stents were piled on top of each other (see OD = 2000 and $4000 \mu \mathrm{m}$ in Figure 11), the highest OSI peaks were located downstream from each congruent pair. On the other hand, when overlapping was incongruent, the highest peak of OSI was located downstream from each of the overlapping struts of the second stent (see Figure 11, blue rectangles in $\mathrm{OD}=3000 \mu \mathrm{m}$ ). In general, more peaks were present for incongruent configurations. For the BVS stent, the peaks are wider and higher for all the studied configurations. Downstream of this zone, the OSI distribution rapidly reverts to that of a well-apposed single stent.
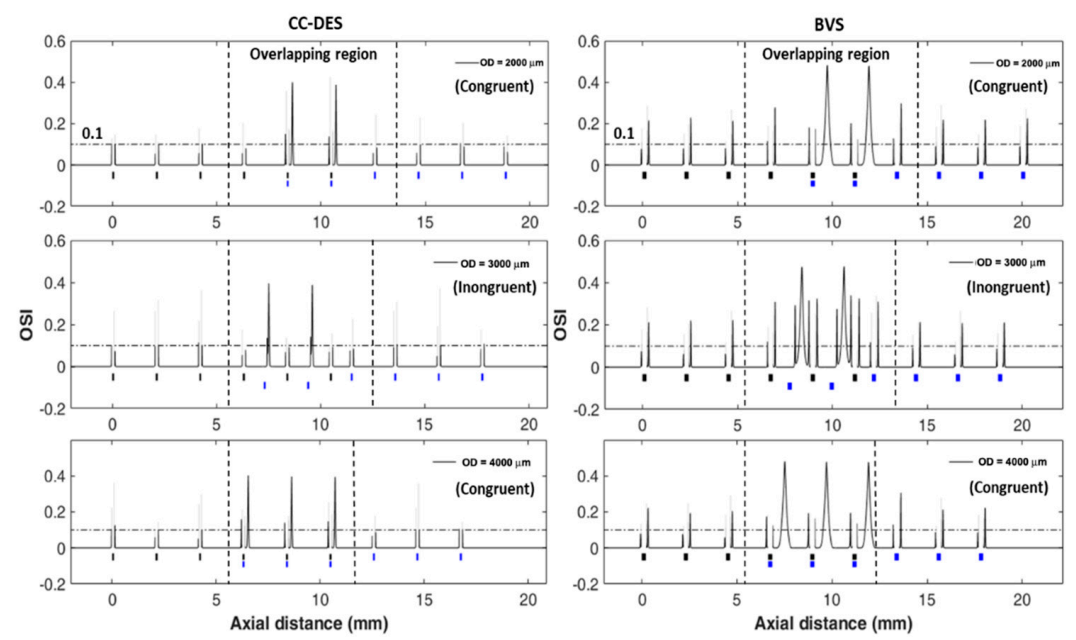

Figure 11. Oscillatory shear index (OSI) distribution for overlapping configuration. For simplicity reasons, three representative configurations are displayed for each strut size. Strut locations on the $\mathrm{X}$-axis are indicated with black and blue rectangles. Notice that axial distance $=0 \mathrm{~mm}$ corresponds to the location of the first stent. Two ranges can be defined: OSI $<0.1$ (Low recirculation) and OSI $>0.1$ (High recirculation). 


\subsubsection{Effect of the Overlapping on the RRT}

Figure 12 displays the RRT distribution of overlapping CC-DES and BVS stents. First, for the set of overlap values studied, the RRT distribution is only modified in this overlap area and not for the upstream (stent 1 ) and downstream (stent 2 ) sections. In the configurations with congruent struts $(\mathrm{OD}=2000 \mu \mathrm{m}$ and $\mathrm{OD}=4000 \mu \mathrm{m})$, in addition to the RRT peaks located in the vicinity of the struts in contact with the arterial wall, another peak appears downstream of the congruent struts. This new peak is less wide but with values higher than the threshold chosen for this study $\left(8 \mathrm{~Pa}^{-1}\right)$. For the configurations with non-congruent struts, the RRT distribution is significantly affected with the appearance of a weak peak upstream of the struts detached from the wall and especially a downstream zone (up to the strut in contact with the arterial wall) with several peaks clearly exceeding the RRT thresholds.
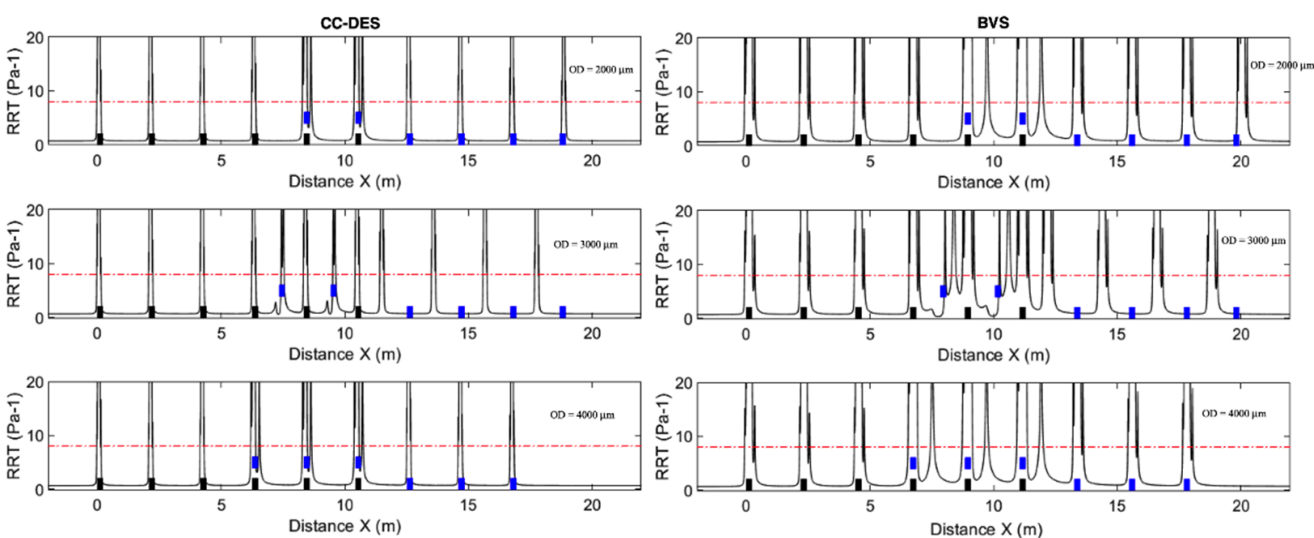

Figure 12. RRT distribution for overlapping configuration. For sake of simplicity, three representative configurations are displayed for each strut size $(\mathrm{OD}=2000 \mu \mathrm{m}, 3000 \mu \mathrm{m}$ and $4000 \mu \mathrm{m})$. Strut locations on the $\mathrm{X}$-axis are indicated with black (upstream stent) and blue rectangles (downstream stent). Notice that axial distance $=0 \mathrm{~mm}$ corresponds to the location of the first stent.

\subsubsection{Relationship between OSI and TAWSS for Overlapping Configuration}

Figure 13 shows the distribution of TAWSS versus OSI for all the configurations including an OSI peak higher than 0.1 in the overlapping region (OD $=2000,2500,3000$, 3500 and $4000 \mu \mathrm{m}$ for both the CC-DES and BVS stents). It can be seen that, similarly as found for malapposition configurations (see Figure 8), high OSI values were always associated with low TAWSS $<0.5 \mathrm{~Pa}$ ).
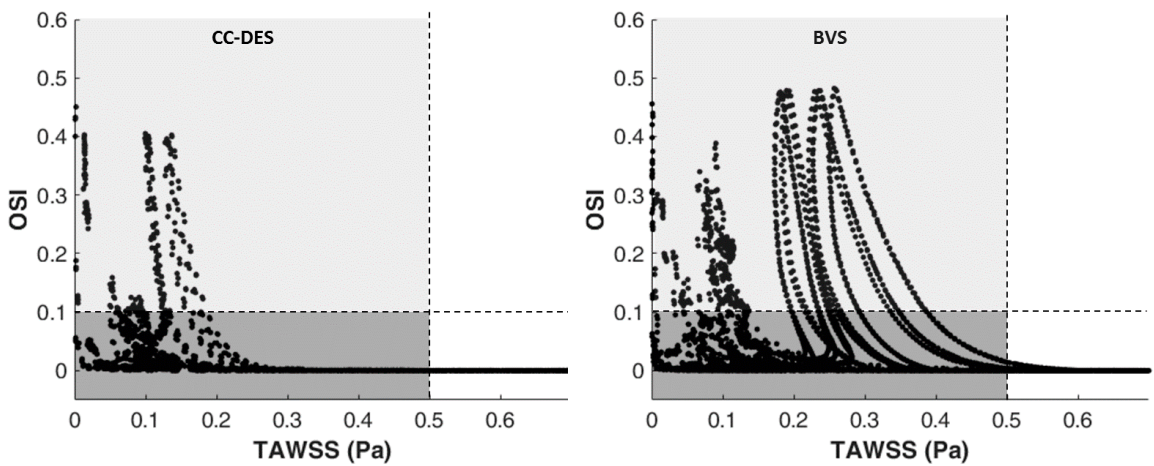

Figure 13. OSI vs. TAWSS plots. Each point represents a nodal solution of the arterial wall. The considered configurations were $\mathrm{OD}=200,2500,3000,3500$ and $4000 \mu \mathrm{m}$ for both stent types. 
3.2.6. Effect of Overlapping Distance on Arterial Wall Extent with a Risk of Restenosis/Thrombus

Figure 14 displays the evolution of the total arterial extension affected by low TAWSS $(<0.5 \mathrm{~Pa})$, high TAWSS $(>0.5 \mathrm{~Pa})$ and high OSI (>0.1) versus overlapping distance (OD). In general, the effect of different OD levels on the arterial length affected by low TAWSS and high OSI was rather constant for both strut sizes but more significant for the BVS stent. Regarding high TAWSS, it did not affect significantly the vessel wall.
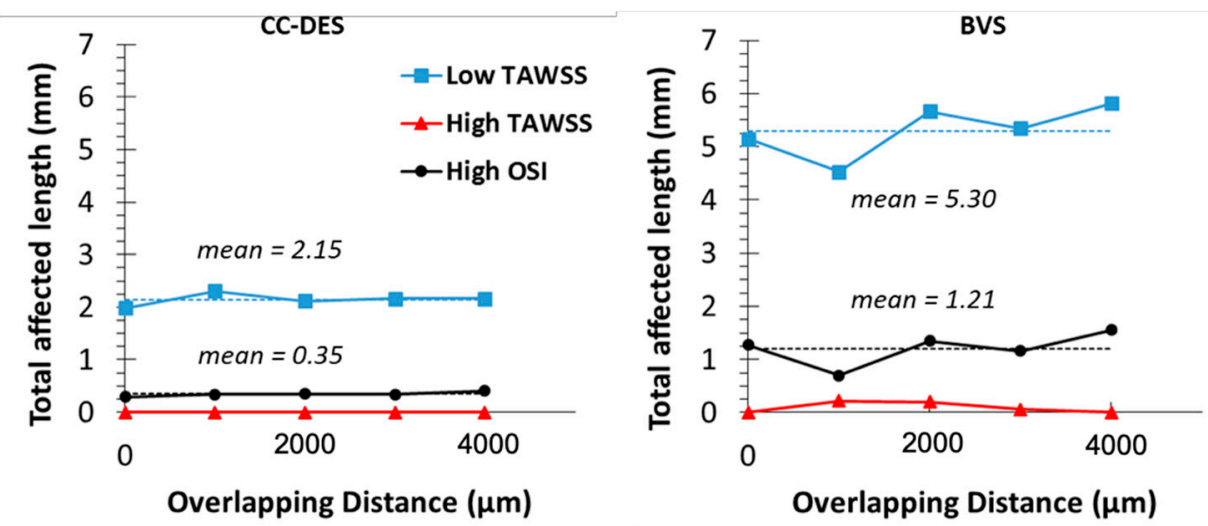

Figure 14. Evolution of affected arterial length vs. overlapping distance (OD).

Overlapping CC-DES stents increased the total arterial extension affected by low TAWSS up to $2.31 \mathrm{~mm}$ (at OD = $2500 \mu \mathrm{m}$ ) and the one affected by high flow oscillation up to $0.41 \mathrm{~mm}$ (at OD $=4000 \mu \mathrm{m}$ ). For overlapping BVS stents, the total affected wall raised up to $5.81 \mathrm{~mm}$ (at OD $=4000 \mu \mathrm{m}$ ) and up to $1.55 \mathrm{~mm}$ (at OD $=3500 \mu \mathrm{m})$ for low TAWSS and high flow oscillation, respectively. Moreover, the increment of wall extension affected by high TAWSS was relatively small for both stent sizes (maximum of $0 \mathrm{~mm}$ and $0.22 \mathrm{~mm}$ for CC-DES and for BVS, respectively). Finally, the increment of wall segments affected by low TAWSS and high OSI were significantly larger for BVS stents, up to 2.47 and 3.48 times respectively (i.e., taking into account the mean total affected lengths shown in Figure 14).

\section{Discussion}

This study investigated the hemodynamic conditions in coronary arteries with malapposed and overlapped stents while considering a pulsatile non-Newtonian blood flow and WSS-related indices computed over a cardiac cycle. The use of axisymmetric CFD models simplified the systematic analysis of each geometry by performing a parametric study with a significant number of computations $(n=30)$. The obtained results help to clarify the impact of different degrees of strut misalignment on local hemodynamics (TAWSS, OSI and RRT).

First, the regions of the vessel wall affected by high OSI were always under low TAWSS for all the studied configurations (see Figures 7 and 14). This suggests that a condition for OSI is the occurrence of low TAWSS as stated by $[8,18,32]$.

\subsection{Malapposed Configuration}

The analysis of the malapposition geometries showed that regions of the arterial wall affected by both low shear stress and oscillatory flow (i.e., TAWSS $<0.5 \mathrm{~Pa}$ and OSI > 0.1) were present for small degrees of malapposition distance (MD). The extension of the vessel affected by high OSI reached a maximum when MD was close to one strut height (i.e., $\mathrm{H}=85 \mu \mathrm{m}$ and $\mathrm{H}=150 \mu \mathrm{m}$ for CC-DES and BVS stents, respectively). With further increments of $\mathrm{MD}$, the region with high flow oscillation decreased until it vanished (see MD $=115 \mu \mathrm{m}$ for CC-DES stent and MD $=300 \mu \mathrm{m}$ for BVS stent in Figure 4). These results are confirmed by the RRT distribution (see Figure 6). Indeed, when the MD values increase (see MD = $115 \mu \mathrm{m}$ for CC-DES stent and MD = $300 \mu \mathrm{m}$ for BVS stent in Figure 6), 
the RRT peaks strongly decrease and fall below the threshold. The areas, in the overlap section, affected by the adverse effect of RRT tend to vanish. In addition, low shear stresses continued to develop on the arterial wall even when the OSI canceled out, indicating that the velocity gradient near the wall was low but the flow was no more oscillatory. These tendencies agree with the conclusions of previous works $[8,10,22,33]$ and can be seen in Figure 8.

With the increment of MD and the shift of recirculation regions downstream from the malapposed struts, the free space near the arterial wall increased and the local resistance to flow decreased. Consequently, fluid accelerated through the gap between the malapposed struts and the vessel wall (see Figure 3) and caused localized regions with high shear stress (i.e., TAWSS $>2.5 \mathrm{~Pa}$, see Figure 4). Moreover, the magnitude of the high shear stress and the size of the affected wall extensions increased gradually with the degree of wall separation (see Figures 4 and 8, respectively), which is consistent with the conclusions of $[6,10]$. Additionally, the presence of consecutive misaligned struts produced a decreasing effect on TAWSS values. It was always particularly enhanced between the first and the second strut (see Figure 4).

The configuration that led to the higher risk of potential restenosis occurred when the malapposed struts were separated from the wall of approximately one strut height (see zone 1 in Figure 8). This configuration promotes the formation of large recirculation zones downstream from each malapposed strut, resulting in abnormally low TAWSS. On the other hand, the risk of potential thrombosis was more significant for configurations with large wall separations due to the occurrence of larger segments with high TAWSS (see zone 3 in Figure 8). In such configurations, the risk of thrombus development had previously been noted by [34]. In the intermediate zone (see zone 2 in Figure 8), the risk of restenosis and thrombosis coexisted. The conclusions were similar for the two studied stents. However, the concerned length is much more important for BVS stent.

\subsection{Overlapping Configuration}

The analysis of the overlapping geometry revealed an important deficit of shear stress (TAWSS $<0.5 \mathrm{~Pa}$ ) compared to non-overlapping segments of the stented artery (see Figure 10), which was in agreement with the results of [17-19]. In general, two congruent struts (i.e., with $\mathrm{OD}=2000 \mu \mathrm{m}$ and $4000 \mu \mathrm{m}$ ) were found to act as a single apposed strut with double height. Consequently, congruent struts produced similar TAWSS distributions than single apposed struts but with more significant hemodynamic disturbances (see $\mathrm{OD}=2000 \mu \mathrm{m}$ and $4000 \mu \mathrm{m}$ in Figure 10). Moreover, the configurations with congruent struts were found to produce a large recirculation area downstream from the stacked struts at the diastolic peak (see Figure 9). As the RRT is a function of the OSI and TAWSS, the RRT provides general information combining the two previous information (see Figure 12). A similar disturbed flow region was identified by $[17,22,35]$ after performing steady-state analyses on realistic and idealized CFD models, respectively. However, our transient studies revealed that, in terms of the hemodynamic effect on the vascular wall over the cardiac cycle, congruent struts configuration was not necessarily worse than incongruent struts configurations. As seen in Figure 14, the total arterial lengths affected by low shear stress (TAWSS $<0.5 \mathrm{~Pa}$ ) and high oscillation (OSI $>0.1)$ are rather constant for all the studied range of overlapping distance. It should be noted that the total stented length varies significantly with the OD value. In fact, this length varies from $18.9 \mathrm{~mm}$ to $16.81 \mathrm{~mm}$ for the CC-DES stent and from 19.50 to $17.35 \mathrm{~mm}$ for the BVS one.

For overlapping configurations, the wall lengths affected by high shear stresses (TAWSS $>2.5 \mathrm{~Pa}$ ) were relatively smaller than for malapposition configurations. Regarding incongruent strut configurations, TAWSS peaks appeared in regions with significant gaps between the vessel wall and overlapping struts (see OD = $3000 \mu \mathrm{m}$ in Figure 10). However, these peaks were considerably lower than those caused by malapposition configurations (see Figure 4). Since the gap between the wall and the overlapping struts is less significant (i.e., $52 \mu \mathrm{m}$ and $107 \mu \mathrm{m}$ for CC-DES and BVS struts, respectively) compared to the cases 
with large MDs (i.e., up to $450 \mu \mathrm{m}$ ), the TAWSS peaks were relatively small and in the order of magnitude of small malapposition distances.

The potential risks of restenosis are relatively similar for all the overlapping struts configurations studied, as highlighted by [36]. As OSI and TAWSS are fluctuating in the non-congruent cases, the distribution of RRT is highly variable and shows several peaks in the overlap area. As seen in Figure 14, low shear stress and flow oscillation always affected the vessel wall for all the studied cases (i.e., OD from 2000 to $4000 \mu \mathrm{m}$ ). On the other hand, the risk of thrombosis seems to be reduced for these configurations.

\subsection{Effect of the Strut Dimensions}

It is obvious that thinner struts (i.e., CC-DES in this study) represent smaller obstacles to blood flow. So, this improves the shear stress distribution and allows a faster flow reattachment between strut cells $[5,37]$. In this work, BVS struts were associated with larger hemodynamic disturbances for all the studied configurations. The RRT plots (See Figures 6 and 12) for malapposition and overlapping stents show the adverse effect of the strut dimensions.

In the case of the correctly apposed stents cases (see MD $=0 \mu \mathrm{m}$ in Figure 4), the BVS struts increased the extension of regions with low shear stress and high oscillatory flow 2.43 times and 2.37 times, respectively. However, both strut sizes allowed flow reattachment to reach normal shear stress values (TAWSS around 1.5 Pa).

Regarding malapposition and overlapping configurations, the performance difference between CC-DES and BVS struts was more notorious. For malapposition cases, the use of BVS struts increased up to 2.9, 1.51 and 3.31 times the wall segments affected by low TAWSS, high TAWSS and high OSI, respectively. Regarding overlapping configurations, the use of BVS struts increased up to 2.47 and 3.48 times the wall segments affected by low TAWSS and high OSI, respectively. These results suggest that, in the case of equal strut misalignment degrees (i.e., malapposition or overlapping), thicker struts will always induce significantly larger hemodynamic disturbances than smaller struts and will increase the risk of restenosis and/or thrombosis.

\section{Study Limitations}

First of all, the use of idealized axisymmetric models disregards the 3D effect that coronary stents could have on the blood flow. The models in the present study are twodimensional, while real blood vessels are three-dimensional. The 2D models assume rotational symmetry and no tangential flow component. However, this component exists in the reality but it is neglected in the study. Additionally, stents are not axisymmetric. For these reasons, the present work is useful to show tendencies of the hemodynamic variables on the malapposition and overlapping rather than provide detailed information on the flow structures and WSS patterns.

Moreover, our model does not consider any arterial curvature (i.e., we considered straight arteries) or residual stenosis that may remain after PCI. These geometric simplifications affect the hemodynamic results. However, the use of realistic 3D models requires significant computational costs, which are not compatible with parametric studies. Furthermore, a 3D model is especially justified for the analysis of a patient-specific configuration. The use of 2D axisymmetric models let us fulfill the objectives of this work which were: (1) to clarify the hemodynamic evolution for different degrees of strut misalignment, and (2) to identify critical configurations that may be associated with restenosis and thrombosis. Such goals can be only be reached with systematic parametric analysis.

In addition, the compliance of the arterial wall was also neglected. However, it is known that stent deployment and atherosclerotic plaque reduce the compliance of the artery wall [38]. Additionally, as demonstrated in the literature [39], the WSS and its related indices are not affected by the vessel compliance for straight arteries. 
Finally, the biological response of the vascular wall was not considered, and only the hemodynamic effects were investigated. Incorporating more complex models to predict drug deposition or thrombus formation [10] could give a deeper insight into this subject.

\section{Clinical Application}

Stent deployment is a challenging task, especially for stenoses with complex configurations (i.e., with excessive lengths, close to bifurcations, concomitant lesions, etc.). Therefore, the ideal stent implantation is difficult to achieve in clinical practice. The fact is that interventional cardiologists frequently encounter incomplete strut apposition and overlapping. The main conclusions found in this study may provide interesting information for cardiologists and stent designers to know: (1) how different degrees of malapposition and overlapping disturb blood flow and (2) which configurations are the most critical ones and their potential link to poor clinical outcomes.

First, this study highlights that malapposed struts will produce the maximal flow recirculation near the artery wall when malapposition distance is close to one strut height (i.e., critical point for restenosis). With further increments of wall separation, recirculation regions will disappear but the artery wall will be subjected to high shear stresses (critical point for thrombosis). Since there is a decreasing effect on shear stress for consecutive struts, the risk of plaque rupture and platelet activation is higher for regions close to the first group of misaligned struts. Second, stent overlapping was more prone to increase the risk of restenosis due to the appearance of segments of the artery wall subjected to low shear stress and flow recirculation. In terms of critical configurations, the risk seems to be comparable for all of them (i.e., incongruent and congruent struts). From a hemodynamic point of view, the best is to avoid overlapping if possible. Indeed, for all overlapping configuration, the extent of the zones where risks of stenosis/thrombus is significantly greater than for malapposed configuration. Finally, thicker struts are more sensitive to strut misalignment problems.

\section{Conclusions}

This axisymmetric numerical study allows evaluation of the risks related to a malapposition or an overlapping stent. The numerical models show that the relative extent of the areas with high risk (restenosis/thrombus) is considerably increased in regions with overlapped stent compared to regions without overlapped stent and even compared to areas of malapposed stent. Since it is generally accepted that low TAWSS (TAWSS $<0.5 \mathrm{~Pa}$ ), high TAWSS (TAWSS $<2.5 \mathrm{~Pa}$ ), high OSI (OSI $<0.1)$ and RRT $>8 \mathrm{~Pa}^{-1}$ are important factors for atherogenesis and thrombogenesis, the results indicate that adverse hemodynamics caused by overlapping stents may be partly responsible for adverse clinical outcomes in patients treated with overlapping stents. The development of risk areas for malapposition is significantly lower than for overlap. In addition, it was shown that the size of the struts has a very negative effect on the development of risk areas. In cases where stent overlap cannot be avoided, deployment strategies should be optimized or new stent designs should be considered to reduce the risk of restenosis.

Author Contributions: Simulations, postprocessing and writing original draft preparation, R.C.; writing original draft preparation, postprocessing, supervision, funding acquisition, project administration, M.L.; simulations, supervision, conceptualization, funding acquisition, manuscript review and editing, M.M.; Conceptualization, data curation, supervision, R.I.P.; Conceptualization, data curation, supervision, G.F., F.D.; Conceptualization, data curation, supervision, resources, project administration, writing, funding acquisition and reviewing original draft, J.O. All authors have read and agreed to the published version of the manuscript.

Funding: This research Project was supported by grants from Labex CAMI-France (project SIMPLE) and the Mexican Council of Science and Technology (CONACYT). M. Malvè was supported by the Spanish Ministry of Economy, Industry and Competitiveness through research project DPI2017-83259R (AEI/FEDER, UE) and by the Department of Economic Development of the Navarra Government through research project PC086-087-088 CONDE. 
Institutional Review Board Statement: Not applicable.

Informed Consent Statement: Not applicable.

Data Availability Statement: Data are available under request to the authors.

Acknowledgments: The support of the Instituto de Salud Carlos III (ISCIII) through the CIBER-BBN initiative is highly appreciated.

Conflicts of Interest: The authors declare no conflict of interest. The funders had no role in the design of the study; in the collection, analyses, or interpretation of data; in the writing of the manuscript, or in the decision to publish the results.

\section{References}

1. Koskinas, K.C.; Chatzizisis, Y.S.; Antoniadis, A.P.; Giannoglou, G.D. Role of Endothelial Shear Stress in Stent Restenosis and Thrombosis. J. Am. Coll. Cardiol. 2012, 59, 1337-1349. [CrossRef]

2. Jaryl, N.; Bourantas, C.V.; Torii, R.; Ang, H.Y.; Tenekecioglu, E.; Serruys, P.W.; Foin, N. Local Hemodynamic Forces After Stenting. Arterioscler. Thromb. Vasc. Biol. 2017, 37, 2231-2242.

3. Byrne, R.A.; Joner, M.; Kastrati, A. Stent Thrombosis and Restenosis: What Have We Learned and Where Are We Going? The Andreas Grüntzig Lecture ESC 2014. Eur. Heart J. 2015, 36, 3320-3331. [CrossRef] [PubMed]

4. Lewis, G. Materials, Fluid Dynamics, and Solid Mechanics Aspects of Coronary Artery Stents: A State-of-the-art Review. J. Biomed. Mater. Res. Part B Appl. Biomater. 2008, 86, 569-590. [CrossRef]

5. Beier, S.; Ormiston, J.; Webster, M.; Cater, J.; Norris, S.; Medrano-Gracia, P.; Young, A.; Cowan, B. Hemodynamics in Idealized Stented Coronary Arteries: Important Stent Design Considerations. Ann. Biomed. Eng. 2016, 44, 315-329. [CrossRef]

6. Foin, N.; Gutiérrez-Chico, J.L.; Nakatani, S.; Torii, R.; Bourantas, C.V.; Sen, S.; Nijjer, S. Incomplete Stent Apposition Causes High Shear Flow Disturbances and Delay in Neointimal Coverage as a Function of Strut to Wall Detachment Distance: Implications for the Management of Incomplete Stent Apposition. Circ. Cardiovasc. Interv. 2014, 7, 180-189. [CrossRef]

7. Räber, L.; Jüni, P.; Löffel, L.; Wandel, S.; Cook, S.; Wenaweser, P.; Togni, M. Impact of Stent Overlap on Angiographic and Long-Term Clinical Outcome in Patients Undergoing Drug-Eluting Stent Implantation. J. Am. Coll. Cardiol. 2010, 55, 1178-1188. [CrossRef] [PubMed]

8. Poon, E.K.W.; Barlis, P.; Moore, S.; Pan, W.H.; Liu, Y.; Ye, Y.; Yuan, X.; Zhu, S.J.; Andrew, S.H. Numerical Investigations of the Haemodynamic Changes Associated with Stent Malapposition in an Idealised Coronary Artery. J. Biomech. 2014, 47, $2843-2851$. [CrossRef] [PubMed]

9. Yoon, H.-J.; Hur, S.-H. Optimization of Stent Deployment by Intravascular Ultrasound. Korean J. Intern. Med. 2012, 27, 30. [CrossRef]

10. Chesnutt, J.K.W.; Han, H.C. Computational Simulation of Platelet Interactions in the Initiation of Stent Thrombosis Due to Stent Malapposition. Phys. Biol. 2016, 13, 016001. [CrossRef]

11. Otsuka, F.; Nakano, M.; Ladich, E.; Kolodgie, F.D.; Virmani, R. Pathologic Etiologies of Late and Very Late Stent Thrombosis Following First-Generation Drug-Eluting Stent Placement. Thrombosis 2012, 1-16. [CrossRef] [PubMed]

12. Cook, S.; Eshtehardi, P.; Kalesan, B.; Raber, L.; Wenaweser, P.; Togni, M.; Moschovitis, A. Impact of Incomplete Stent Apposition on Long-Term Clinical Outcome after Drug-Eluting Stent Implantation. Eur. Heart J. 2012, 33, 1334-1343. [CrossRef]

13. Wentzel, J.J.; Whelan, D.M.; van der Giessen, W.J.; van Beusekom, H.M.M.; Andhyiswara, I.; Serruys, P.W.; Slager, C.J.; Krams, R. Coronary Stent Implantation Changes 3-D Vessel Geometry and 3-D Shear Stress Distribution. J. Biomech. 2000, 33, 1287-1295. [CrossRef]

14. LaDisa, J.F.; Guler, I.; Olson, L.E.; Hettrick, D.A.; Kersten, J.R.; Warltier, D.C.; Pagel, P.S. Three-Dimensional Computational Fluid Dynamics Modeling of Alterations in Coronary Wall Shear Stress Produced by Stent Implantation. Ann. Biomed. Eng. 2003, 31, 972-980. [CrossRef]

15. Martin, D.M.; Murphy, E.A.; Boyle, F.J. Computational Fluid Dynamics Analysis of Balloon-Expandable Coronary Stents: Influence of Stent and Vessel Deformation. Med. Eng. Phys. 2014, 36, 1047-1056. [CrossRef] [PubMed]

16. Brindise, M.C.; Chiastra, C.; Burzotta, F.; Migliavacca, F.; Vlachos, P.P. Hemodynamics of Stent Implantation Procedures in Coronary Bifurcations: An In Vitro Study. Ann. Biomed. Eng. 2017, 45, 542-553. [CrossRef] [PubMed]

17. Rikhtegar, F.; Wyss, C.; Stok, K.S.; Poulikakos, D.; Müller, R.; Kurtcuoglu, V. Hemodynamics in Coronary Arteries with Overlapping Stents. J. Biomech. 2014, 47, 505-511. [CrossRef]

18. Charonko, J.; Karri, S.; Schmieg, J.; Prabhu, S.; Vlachos, P. In Vitro Comparison of the Effect of Stent Configuration on Wall Shear Stress Using Time-Resolved Particle Image Velocimetry. Ann. Biomed. Eng. 2010, 38, 889-902. [CrossRef]

19. Chiastra, C.; Morlacchi, S.; Gallo, D.; Morbiducci, U.; Cardenes, R.; Larrabide, I.; Migliavacca, F. Computational Fluid Dynamic Simulations of Image-Based Stented Coronary Bifurcation Models. J. R. Soc. Interface 2013, 10, 20130193. [CrossRef]

20. Foin, N.; Lu, S.; Jaryl, N.; Bulluck, H.; Hausenloy, D.; Wong, P.; Virmani, R.; Joner, R. Stent Malapposition and the Risk of Stent Thrombosis: Mechanistic Insights from an in Vitro Model. EuroIntervention 2017, 13, e1096-e1098. [CrossRef] 
21. Chiastra, C.; Wu, W.; Dickerhoff, B.; Aleiou, A.; Dubini, G.; Otake, H.; Migliavacca, F.; LaDisa, J.F. Computational Replication of the Patient-Specific Stenting Procedure for Coronary Artery Bifurcations: From OCT and CT Imaging to Structural and Hemodynamics Analyses. J. Biomech. 2016, 49, 2102-2111. [CrossRef]

22. Kolandaivelu, K.; Swaminathan, R.; Gibson, W.J.; Kolachalama, V.B.; Nguyen-Ehrenreich, K.L.; Giddings, V.L.; Coleman, L.; Wong, G.K.; Edelman, E.R. Stent Thrombogenicity Early in High-Risk Interventional Settings Is Driven by Stent Design and Deployment and Protected by Polymer-Drug Coatings. Circulation 2011, 123, 1400-1409. [CrossRef] [PubMed]

23. Davies, J.E.; Whinnett, Z.I.; Francis, D.P.; Manisty, C.H.; Aguado-Sierra, J.; Willson, K.; Foale, R.A. Evidence of a Dominant Backward-Propagating 'Suction' Wave Responsible for Diastolic Coronary Filling in Humans, Attenuated in Left Ventricular Hypertrophy. Circulation 2006, 113, 1768-1778. [CrossRef] [PubMed]

24. Pinto, S.I.; Campos, J.B. Numerical study of wall shear stress-based descriptors in the human left coronary artery. Comput. Methods Biomech. Biomed. Eng. 2016, 19, 1443-1455. [CrossRef] [PubMed]

25. Paisal, M.S.A.; Taib, I.; Ismail, A.E.; Tajul Arifin, A.M.; Mahmod, M.F. Evaluation System on Haemodynamic Parameters for Stented Carotid Artery: Stent Pictorial Selection Method. Int. J. Integr. Eng. 2019, 11. Available online: https://publisher.uthm. edu.my/ojs/index.php/ijie/article/view/3117 (accessed on 10 February 2021).

26. Malek, A.M.; Alper, S.L.; Izumo, S. Hemodynamic Shear Stress and Its Role in Atherosclerosis. JAMA 1999, 282, 2035. [CrossRef]

27. Murphy, J.; Boyle, F. Predicting Neointimal Hyperplasia in Stented Arteries Using Time-Dependant Computational Fluid Dynamics: A Review. Comput. Biol. Med. 2010, 40, 408-418. [CrossRef]

28. Samady, H.; Eshtehardi, P.; McDaniel, M.C.; Suo, J.; Dhawan, S.S.; Maynard, C.; Timmins, L.H.; Quyyumi, A.A.; Giddens, D.P. Coronary Artery Wall Shear Stress Is Associated With Progression and Transformation of Atherosclerotic Plaque and Arterial Remodeling in Patients With Coronary Artery Disease. Circulation 2011, 124, 779-788. [CrossRef]

29. Bluestein, D.; Gutierrez, C.; Londono, M.; Schoephoerster, R.T. Vortex Shedding in Steady Flow through a Model of an Arterial Stenosis and Its Relevance to Mural Platelet Deposition. Ann. Biomed. Eng. 1999, 27, 763-773. [CrossRef]

30. Zarins, C.K.; Don, P.; Giddens, B.K.; Bharadvaj, V.S.; Robert, F.M.; Seymour, G. Carotid Bifurcation Atherosclerosis. Circ. Res. 1983, 53, 14 .

31. Williams, A.R.; Koo, B.K.; Gundert, T.J.; Fitzgerald, P.J.; LaDisa, J.F. Local Hemodynamic Changes Caused by Main Branch Stent Implantation and Subsequent Virtual Side Branch Balloon Angioplasty in a Representative Coronary Bifurcation. J. Appl. Physiol. 2010, 109, 532-540. [CrossRef] [PubMed]

32. Katritsis, D.G.; Theodorakakos, A.; Pantos, I.; Gavaises, M.; Karcanias, N.; Efstathopoulos, E.P. Flow Patterns at Stented Coronary Bifurcations: Computational Fluid Dynamics Analysis. Circ. Cardiovasc. Interv. 2012, 5, 530-539. [CrossRef]

33. Chen, W.X.; Poon, E.K.W.; Thondapu, V.; Hutchins, N.; Barlis, P.; Ooi, A. Haemodynamic Effects of Incomplete Stent Apposition in Curved Coronary Arteries. J. Biomech. 2017, 63, 164-173. [CrossRef]

34. Brown, J.; O’Brien, C.C.; Lopes, A.C.; Kolandaivelu, K.; Edelman, E.R. Quantification of thrombus formation in malapposed coronary stents deployed in vitro through imaging analysis. J. Biomech. 2018, 71, 296-301. [CrossRef]

35. Rikhtegar, F.; Edelman, E.R.; Olgac, U.; Poulikakos, D.; Kurtcuoglu, V. Drug deposition in coronary arteries with overlapping drug-eluting stents. J. Control. 2016, 238, 1-9. [CrossRef]

36. Antoniadis, A.P. Biomechanical Modeling to Improve Coronary Artery Bifurcation Stenting: Expert Review Document on Techniques and Clinical Implementation. JACC Cardiovasc. Interv. 2015, 8, 1281-1296. [CrossRef] [PubMed]

37. Jiménez, J.M.; Davies, P.F. Hemodynamically Driven Stent Strut Design. Ann. Biomed. Eng. 2009, 37, 1483-1494. [CrossRef]

38. Yong, A.S.C.; Javadzadegan, A.; Fearon, W.F.; Moshfegh, A.; Lau, J.K.; Nicholls, S.; Martin, K.C.; Kritharides, L. The Relationship between Coronary Artery Distensibility and Fractional Flow Reserve. Edited by Michael J Lipinski. PLoS ONE 2017, 12, e0181824. [CrossRef] [PubMed]

39. Chiastra, C.; Migliavacca, F.; Martínez, M.A.; Malvè, M. On the Necessity of Modelling Fluid-Structure Interaction for Stented Coronary Arteries. J. Mech. Behav. Biomed. Mater. 2014, 34, 217-230. [CrossRef] 